\title{
Raças Humanas como uma Questão Sociocientífica (QSC): implicações na formação de professores de ciências
}

\author{
Human Races as a Socio-Scientific Issue (SSI): \\ implications for the training of science teachers
}

iD Thabata Rodrigues de Carvalho'

Dataly Carvalho Lopes ${ }^{2}$

\begin{abstract}
'Universidade Federal de São Carlos (UFSCar), Programa de Pós-Graduação em Educação em Ciências, e Matemática, Araras, SP, Brasil. Autora correspondente: thabatarodrigues@yahoo.com.br

${ }^{2}$ Universidade Federal de São Carlos (UFSCar), Centro de Ciências Agrárias, Araras, SP, Brasil.
\end{abstract}

Resumo: Embora diversos pesquisadores argumentem pela necessidade de uma Educação CTS, ainda são necessários estudos no campo do ensino de ciências que discutam problemáticas humanitárias nesta perspectiva, tal como o racismo, que proporcionem o desenvolvimento de valores como justiça e igualdade. Para tanto, investigamos as implicações da questão sociocientífica 'Raças Humanas' na formação de professores de ciências. Como resultado, destacamos a abrangência da temática envolvendo as dimensões ética, moral e valorativa do conhecimento científico e a contribuição dos espaços de reflexões coletivas como potenciais para o desenvolvimento profissional docente. Assim, consideramos que tal abordagem tem muito a contribuir à formação de professores antirracistas.

Palavras-chave: Racismo; Educação CTS; Ensino de ciências; QSC; Problemas socioeducacionais.

Abstract: Although different researchers argue for the need for STS Education, studies in the field of Science Education that discuss humanitarian issues in this perspective, such as racism, are still needed. These discussions are important for the development of values such as justice and equality. Therefore, we investigated the implications of SSI 'Human Races' in the education of Science teachers. As a result, we highlight the scope of the theme involving the ethical, moral and evaluative dimensions of scientific knowledge and the contribution of spaces for collective reflections as potential factors in the development of teaching knowledge. Thus, we believe that this approach has a lot to contribute to education anti-racist teachers. problems.

Keywords: Racism; STS education; Science teaching; SSI; Socio-educational

Recebido em: 07/07/2020

Aprovado em: 17/03/2021 


\section{Introdução}

As questões sociocientíficas envolvem temáticas controvérsias que têm uma base científica, mas estão com frequência à margem desse conhecimento, porque possuem uma grande relevância social, lidam com informações incompletas e evidências científicas conflitantes. Essas questões estão em evidência na mídia e demandam uma análise na qual custo, benefício, riscos e valores conflitam (RATCLIFFE; GRACE, 2003).

De acordo com estas definições, é possível compreender a temática 'Raças Humanas' como uma questão cientificamente baseada, pois embora não seja nossa intenção argumentar que o racismo, em toda sua complexidade, seja um produto das ciências, a ciência moderna, tida como neutra, contribuiu para a sua legitimação e promoção embasando políticas de eugenia ao redor do mundo. O programa científico eugênico, liderado por Leonard Darwin, filho de Charles Darwin, foi central para a implementação das políticas eugênicas. A exemplo das produções desse programa está o tratado para o melhoramento da raça intitulado The need of eugenic reform, publicado em 1926 (BIZZO, 1995; MACIEL, 1999). Por outro lado, é necessário desenvolver críticas contundentes a estes aspectos conflituosos da ciência, ao mesmo tempo em que devemos ter o cuidado para não ceder à descrença no desenvolvimento científico e aos argumentos infundados dos movimentos anticiência.

Neste sentido, considerando o fato de que o racismo é crime no Brasil, podemos ser levados a pensar que a temática 'Raças Humanas' não é controversa. Qualquer ato de racismo está sujeito à punição prevista em lei (BRASIL, 1951, 1989). Entretanto, se nos demorarmos em sua compreensão, veremos que inúmeras controvérsias se revelam, quando a legislação conflita com o racismo estrutural na sociedade, seja em uma piada nos programas de humor, nos dados da violência no Brasil, na distribuição de vagas de emprego e as posições mais valorizadas, seja na representação de negros ao discutirem como especialistas sobre temas de ciência, tecnologia e literatura ou mesmo nos diferentes posicionamentos científicos sobre o conceito de 'Raças Humanas'.

Assim, nos Atlas da Violência de 2017 e 2018 (CERQUEIRA et al., 2017, 2018) é explicitada uma alarmante realidade. Considerando os dados apresentados nestes documentos, é como se negros e brancos vivessem em países e realidades totalmente distintas. A situação vivenciada pela juventude negra brasileira é comparada a uma situação de guerra, uma vez que esse público representa $71 \%$ das vítimas de homicídio em nosso país (CERQUEIRA et al., 2017). As taxas de mortalidade feminina também revelaram a desigualdade racial, visto que no período de 2005 a 2015, enquanto houve uma redução de 7,4 \% desse índice para mulheres não negras, por outro lado, houve um aumento de $22 \%$ para mulheres negras. Esses dados contradizem o discurso da democracia e da igualdade racial que prevalece no ideário da população brasileira.

Nesse cenário de intensas contradições, nos convém olhar para os diferentes posicionamentos científicos que envolvem a temática. Enquanto há um consistente consenso entre as ciências biológicas sobre a inexistência de raças para a nossa espécie, no âmbito das ciências sociais, essa categorização é há muito tempo consolidada. Segundo Dias et al. (2015) um intenso debate entre esses dois campos acadêmicos foi fomentado pela publicação de Pena et al. (2000) intitulada O retrato molecular brasileiro, 
entre outras publicações que advogam pelo banimento do termo raças do campo da medicina (PENA, 2005). Autores como Santos e Maio (2004) questionam as 'boas intenções' dessa publicação e argumentam que o banimento do termo raças pode contribuir ainda mais para o silenciamento do racismo e a promoção do mito da democracia racial, com base no argumento da mestiçagem de nossa população. Para muitos, essa discussão está encerrada por estar cientificamente comprovada, ainda que essa 'comprovação' se limite ao âmbito das ciências naturais, a máxima de que todos somos iguais. Porém, tal ciência, em sua posição de poder, mais uma vez tem a palavra final, contradizendo agora seus próprios ensinamentos, outrora racistas? Compreendemos que essa questão é muito mais complexa que isso, e tão mais ampla deveria ser sua discussão.

Seguindo essas ideias, de acordo com Munanga (2012), o racismo é um crime perfeito em nosso país, pois embora muitos confirmem a existência do racismo na sociedade brasileira, poucos se assumem racistas, ou seja, um racismo sem racistas. $A$ partir disso, consideramos que nesse aspecto reside a maior controvérsia dessa temática. Isso, porque um racismo sem racistas revela a existência de diferentes compreensões sobre quem é racista e como o racismo se manifesta. Revela ainda, a invisibilidade da questão e quanto carecemos dessas discussões.

Frente a isso, questionamos: qual seria o papel da formação de professores de ciências na promoção de uma sociedade antirracista? A cada dia somos confrontados com interesses diversos sobre os encaminhamentos do ensino de ciências, que levam a objetivos concorrentes na maioria das vezes, uma vez que o tempo é um recurso limitado.

Assim, partindo das inquietações até aqui apresentadas, buscamos com esse trabalho discutir a questão norteadora: quais as implicações da discussão sobre 'Raças Humanas' e seus aspectos sociocientíficos na formação de professores de ciências? Neste artigo, apresentamos um recorte dos resultados da pesquisa de mestrado da primeira autora, destacando as principais conclusões encontradas.

\section{A formação de professores de ciências na interface teoria da ação comunicativa e questões sociocientíficas}

Considerando os modelos de formação de professores que orientaram as pesquisas em formação docente no Brasil, compreendemos que este é um campo de constantes tensões e ambiguidades. As instituições governamentais e escolares, os pesquisadores da área do ensino de ciências humanas e os das ciências naturais têm interesses conflitantes e diferentes posicionamentos (BAROLLI; VILLANI, 2015). Dentre as diferentes perspectivas de formação docente, assumimos a perspectiva crítica e lançamos mão da teoria da ação comunicativa (TAC) desenvolvida por Jürgen Habermas (HABERMAS, 2012a, 2012b) como fundamento para compreensão dos processos educacionais, assim como fizeram diversos autores, tal como Prestes (1996) e Mühl (2011).

Segundo Mühl (2011, p. 1048), na educação crítica que se fundamenta na perspectiva habermasiana 
[...] a escola é desafiada a promover a reflexão sobre os pressupostos e os interesses que estão na base dos conhecimentos e das práticas que desenvolve cotidianamente, possibilitando que toda a comunidade escolar se torne uma organização que fundamente suas ações científicas, éticas e estéticas na prática comunicativa. É na prática cotidiana da comunicação, na busca do entendimento sem coação, que se configura o processo de libertação da humanidade, pois esta continua a depender da inteligibilidade e da decisão coletiva baseada em argumentos racionais. (MÜHL, 2011, p. 1048).

Neste sentido, a educação crítica fundamentada na teoria de Habermas, propõe à reestruturação dos processos educativos a partir da intersubjetividade. No exercício da comunicação, os agentes devem orientar-se pela busca por entendimento. A partir desse princípio fundamental se constitui a ação comunicativa, conceito que discutiremos a seguir (HABERMAS, 2012a). Tal abordagem parte da concepção de que os sujeitos envolvidos nesses processos aprendem mutuamente no exercício da comunicação (GOMES, 2009). A formação de professores assim orientada confere a esses agentes o papel ativo em seus processos formativos, de modo a promover a sua emancipação como sujeitos autônomos no exercício da profissão.

Segundo a teoria habermasiana (HABERMAS, 2012a, 2012b), as ações podem ser classificadas em quatro tipos: regulada por normas; dramatúrgica; teleológica e comunicativa. A ação regulada por normas corresponde a quando os membros de um grupo agem segundo valores comuns. Nesse modo de ação, o objetivo é cumprir uma norma ou satisfazer a expectativa de comportamento vigente. Na ação dramatúrgica, os agentes representam um público uns para os outros e assumem uma imagem de si controlando o grau de exposição de seus pensamentos, opiniões, intenções, e demais aspectos de suas subjetividades. A ação teleológica corresponde ao modo de ação no qual os atores escolhem como agir em cada situação tendo em vista um propósito, alcançar um fim esperado. Cada decisão é tomada a partir de uma estimativa de êxito. Esse modo de ação pode ser ampliado e entendido como um agir estratégico. Por fim, a ação comunicativa é quando dois ou mais atores interagem orientados ao entendimento de uma situação de ação. Nesse modo de ação, os agentes entram em negociação em busca de consenso para as mais diferentes questões.

A fala, considerada um modo de ação, pode ser classificada segundo esses mesmos critérios. Segundo Habermas (2012a, 2012b), a resolução dos problemas e conflitos sociais passa pelos processos comunicativos. Para Habermas, o exercício da linguagem é uma forma de agir no mundo e o autor ainda classifica os atos de fala como ilocucionários ou locucionários. O ato locucionário é referente à exteriorização linguística dotada de sentido. O que difere o ato locucionário do ato ilocucionário é, sobretudo, a intencionalidade do falante alcançar entendimento. Ou seja, o ato locucionário remete à dimensão linguística propriamente dita, e a ela se resume, enquanto o ato ilocucionário expressa a força de se fazer compreendido.

As ações comunicativas devem atender a três critérios universais para serem assim consideradas. Esses critérios são denominados pretensões de validade e dizem que os atos de fala devem ser: (a) verdadeiros, representando algo que exista no mundo; (b) atender às normas vigentes socialmente; (c) serem honestos quanto à subjetividade do falante, a intenção expressa pelo falante deve ser correspondente ao que ele pensa. 
A partir desses conceitos, a teoria da sociedade de Habermas nos fornece subsídios para a compreensão e a ação social. Uma proposta educacional comunicativa nos dá elementos para um ensino que seja efetivamente democrático, livre de coações e que promova a emancipação dos sujeitos. Em busca de entendimento e consenso sobre as mais diferentes questões, dar voz a todos os sujeitos envolvidos no processo é de fundamental importância. Esses aspectos conferem aos processos formativos uma visão mais ampla e contextualizada, que extrapole os aspectos técnicos e instrumentais do ensino e da aprendizagem.

Com isso, a análise do contexto educacional a partir desse referencial nos possibilita a identificação das patologias sociais que nele se manifestam (PRESTES, 1996). Assim, percebemos a aproximação entre a filosofia habermasiana e o campo da formação de professores de ciências como potencial para identificar e combater o racismo, bem como as diversas patologias presentes no ambiente escolar para promoção da justiça social. Deste modo, podemos contribuir não somente para a luta antirracista, mas também para o respeito à diversidade em seus diversos aspectos.

No contexto da formação de professores de ciências, a temática racial pode ser colocada em pauta sob uma ótica ainda pouco explorada, ao serem considerados seus aspectos sociocientíficos. Segundo Lopes (2010, p. 65), o ensino de ciências a partir da abordagem de questões sociocientíficas tem como premissa "[...] os sujeitos como responsáveis por suas ações". Assim, tem contribuído para o desenvolvimento da autonomia dos sujeitos, um importante aspecto da formação docente. Entretanto, vale ressaltar que a autonomia a qual nos referimos é aquela que se constitui na intersubjetividade e não deve ser compreendida como um processo de individualização e isolamento do professor (CONTRERAS, 2002). Deste modo, o processo de ensino não se baseia na transmissão de conhecimentos científicos como um produto inquestionável, mas na constante análise crítica desses conhecimentos.

Nesta investigação, propomos a discussão da temática 'Raças Humanas' como uma questão sociocientífica (QSC), também buscamos aproximar a teoria crítica habermasiana da formação de professores de ciências. Optamos por nos referir a essa temática entre aspas com o intuito de reforçar o caráter controverso da questão. Além disso, o uso do termo raça na literatura das ciências sociais, seja com ou sem a utilização de aspas, claramente se refere à espécie humana. Neste trabalho, no entanto, sentimos a necessidade de complementar o termo, devido à sua utilização para diversas outras espécies no contexto das ciências naturais.

Contudo, justificamos o desenvolvimento dessa investigação, a partir da necessidade de inovação no campo do ensino de ciências. São recentes as pesquisas dessa área que se voltaram à formação docente e consideraram os aspectos éticos, morais e valorativos envolvidos na ciência. Deste modo, a produção de novos conhecimentos é necessária para fornecer aos professores elementos para enfrentar a difícil realidade em que desempenham seu trabalho.

Embora não exista uma relação direta entre a formação e a prática docente, a análise de riscos, o raciocínio ético, a argumentação, possibilitados mediante o caráter controverso dessa questão, contribuem para o desenvolvimento do pensamento crítico e moral desses agentes e, mais do que isso, possibilitam sensibilizá-los quanto ao papel que desempenham e a responsabilidade que compartilham enquanto professores de ciências. 


\section{Aspectos metodológicos da pesquisa}

Esta pesquisa foi desenvolvida de acordo com métodos e referenciais qualitativos. A pesquisa qualitativa tem como fonte de dados o ambiente natural e se utiliza do próprio pesquisador como ferramenta de sua constituição. Nessa abordagem, preocupa-se muito mais com o processo do que com o produto (SOMEKH; LEWIN, 2015). A estratégia metodológica para a constituição dos dados e análise dos resultados foi a pesquisa participante. Para registro dos dados, foram utilizadas anotações em diário de campo e gravações audiovisuais das discussões.

A pesquisa participante surgiu da crítica aos modelos positivistas de produção do conhecimento, que atendiam principalmente aos interesses hegemônicos e pouco dialogavam com as questões sociais (GAJARDO, 1987). Na pesquisa participante, o pesquisador se insere no contexto sociocultural a ser investigado e junto ao grupo "pesquisado" busca identificar e solucionar problemas, estabelecendo assim uma relação mais horizontal (SCHMIDT, 2006).

Evidencia-se que a pesquisa participante objetiva solucionar problemas, promover conscientização política e produzir conhecimentos, ela logra tais objetivos mediante a legitimação do saber prático do cotidiano, porém sem prescindir dos conhecimentos científicos que são utilizados como meio para desocultar a lógica subjacente a esses saberes comuns. Compete ao pesquisador fazer tal aproximação, tendo em vista que ele desempenha dois papéis na pesquisa: pesquisador e participante. (LONGAREZI; SILVA, 2013, p. 220).

Nesse sentido, a pesquisa participante se aproxima da teoria crítica habermasiana, por ser um processo investigativo crítico e democrático, por meio do qual os sujeitos podem (re) pensar coletivamente as problemáticas sociais, visando transformá-las. Diferentemente das pesquisas guiadas pela racionalidade técnica, nas quais os pesquisadores disponibilizam roteiros e o professor se limita à sua execução, nessa perspectiva o professor é levado à produção de conhecimento, enquanto o pesquisador, ao contexto da sala de aula.

No campo da formação de professores, a pesquisa participante busca o rompimento da dicotomia teoria e prática que fortalece a concepção de que ao professor caberia apenas o papel de execução técnica do ensino (LONGAREZI; SILVA, 2013).

A combinação de interpretações e a composição de saberes nada mais é do que a articulação de pontos de vista, vozes e diferenças tendo em vista a atribuição de sentido àquilo que se investiga, àquilo que justifica a investigação e ao encontro que encarna e realiza suas possibilidades e seus desdobramentos. Neste empreendimento, o pesquisador encarrega-se de tarefas diferenciadas e assume responsabilidades atadas ao fato de ter sido dele, na maioria das vezes, a iniciativa do contato, bem como a proposição inicial de uma pauta de trabalho. (SCHMIDT, 2006, p. 36).

Assim, a pesquisa educacional crítica, voltada à abordagem do conceito de raças como uma QSC, pode contribuir para acusar patologias sociais resultantes das distorções e reduções do processo comunicativo e preparar os professores para lidar 
com eventuais problemas. Deste modo, podemos enriquecer a formação de professores de ciências, preparando-os para lidar com diversas problemáticas que se manifestam no cotidiano escolar, tal como o preconceito racial e, além disso, contribuir para a transformação da prática da própria professora pesquisadora por meio da constante reflexão ao longo do processo de planejamento, ação e observação.

\section{Sobre o contexto da pesquisa}

Essa pesquisa foi desenvolvida no âmbito de uma Atividade Curricular de Integração Ensino, Pesquisa e Extensão (ACIEPE) na Universidade Federal de São Carlos (UFSCar), campus Araras, SP. As ACIEPEs, segundo edital publicado pela Próreitoria de Extensão da UFSCAR, são componentes complementares do currículo que visam proporcionar experiências educativas, culturais e científicas, articulando Ensino, Pesquisa e Extensão (UNIVERSIDADE FEDERAL DE SÃO CARLOS, 2018). Sendo assim, elas podem abranger um público diversificado: alunos da graduação, técnicos ou professores da rede de ensino, ou seja, públicos internos e externos à UFSCar.

Foram participantes da ACIEPE onze pessoas, dentre as quais, quatro professoras em formação continuada, e sete licenciandos, matriculados nos cursos de licenciatura do Campus da UFSCar de Araras.

O percurso de formação foi desenvolvido no mês de março de 2018. As atividades totalizaram 60 horas, das quais 30 foram presenciais e 30 não presenciais. Nessas atividades, tivemos como objeto de estudo a abordagem de questões sociocientíficas no ensino de ciências. Para esta investigação, consideramos os dados referentes à discussão sobre 'Raças Humanas' no ensino de ciências, buscando compreender os diferentes aspectos biológicos, sociais, éticos, valorativos, além de suas implicações no ensino de ciências.

Ao longo da ACIEPE, cada participante foi convidado à reflexão e investigação sobre as possibilidades e também as limitações da inserção da discussão sobre a QSC 'Raças Humanas' para o ensino de ciências. Suas impressões e observações eram registradas em um diário de bordo. Os momentos de atividades não presenciais (NP18) consistiram em investigações e estudo individual que, na maioria das vezes, eram instigados e direcionados por questões e problematizações do grupo. Nos momentos presenciais, cada participante trazia questões e contribuições para a reflexão coletiva. A cada encontro a professora pesquisadora também trazia contribuições com o propósito de fomentar e alimentar as discussões, além de trazer perspectivas diversas que poderiam não ser contempladas pelo grupo. A sequência das atividades da ACIEPE estão registradas no quadro 1 . 
Quadro 1 - Sequência de atividades da Atividade Curricular de Integração Ensino, Pesquisa e Extensão (ACIEPE)

\begin{tabular}{|l|l|}
\hline \multicolumn{1}{|c|}{ Momentos } & \multicolumn{1}{c|}{ Atividades realizadas } \\
\hline Encontro 1 & Compartilhando narrativas: apresentações pessoais e estreitamento das relações intersubjetivas. \\
\hline NP1 & Investigando o racismo no cotidiano: a sensibilização do olhar. \\
\hline Encontro 2 & $\begin{array}{l}\text { 'Raças Humanas' e as Questões Sociocientíficas no ensino de Ciências: conteúdos curriculares } \\
\text { e possíveis aproximações. }\end{array}$ \\
\hline NP2 & Investigando Questões Sociocientíficas potenciais para o ensino de Ciências. \\
\hline Encontro 3 & $\begin{array}{l}\text { Síntese do esforço científico envolvendo a temática 'Raças Humanas'. Controvérsias e divergências } \\
\text { sobre posicionamentos das Ciências Biológicas e Ciências Sociais. Análise de reportagens. }\end{array}$ \\
\hline NP3 & Exercício de seleção e caracterização de uma Questão Sociocientífica. \\
\hline Encontro 4 & Aspectos históricos e sociais da QSC 'Raças Humanas'. \\
\hline NP4 & Exercício de seleção e caracterização de uma Questão Sociocientífica. \\
\hline Encontro 5 & $\begin{array}{l}\text { Caracterização de Questões Sociocientíficas: compartilhando resultados e discussões com } \\
\text { o grupo. }\end{array}$ \\
\hline NP5 & $\begin{array}{l}\text { Leitura do artigo Genética, raça, e políticas de ações afirmativas a partir de questões sociocientíficas } \\
\text { (DIAS et al., 2015). }\end{array}$ \\
\hline Encontro 6 & Política de ações afirmativas. \\
\hline NP6 & Momento de investigação e reflexão individual. \\
\hline Encontro 7 & Políticas de ações afirmativas: raça, racismo e direitos humanos? Estudo dirigido. \\
\hline NP7 & Momento de investigação e reflexão individual. \\
\hline Encontro 8 & Elaboração de propostas de ensino. \\
\hline NP8 & Produção de narrativa. \\
\hline Encontro 9 & Exercício de ação comunicativa: avaliação do percurso formativo. \\
\hline
\end{tabular}

Fonte: elaborado pelas autoras.

\section{Análise dos dados}

Foram elementos de nossas análises os momentos de interação linguística entre os participantes, que aconteceram principalmente nos momentos reservados para a discussão do grupo. Em cada encontro presencial, pelo menos metade da carga horária era destinada para momentos comunicativos, nos quais as discussões envolviam tanto o conteúdo abordado pela professora pesquisadora, quanto questões referentes às investigações e reflexões de cada participante.

Ao longo das análises, buscamos compreender nossos dados quanto ao seu conteúdo pragmático e proposicional. No nível proposicional, buscamos evidenciar os conteúdos sociocientíficos da temática em discussão. No nível pragmático, buscamos evidenciar a intencionalidade dos atos de fala, com o intuito de discutir as possibilidades advindas do processo comunicativo para a formação docente. Além disso, buscamos evidenciar aspectos relevantes para nossa investigação e as possibilidades advindas da discussão sobre a temática 'Raças Humanas' e seus aspectos sociocientíficos.

\section{Resultados e discussões}

Como primeira ação, buscamos estabelecer vínculos de confiança e favorecer o desenvolvimento de um espaço formativo, onde todos se sentissem confortáveis para se posicionarem ao longo das discussões. Esse contato inicial nos possibilitou conhecer o perfil de cada agente de pesquisa, considerando: formação; gênero; grupos de pesquisa ou coletivos dos quais já participou ou ainda participa; projetos 
em que se envolveu; dentre outros aspectos que julgaram importantes compartilhar com o grupo. Essa caracterização detalhada não será exposta, buscando preservar em anonimato a identificação dos participantes. Então, optamos por elencar os agentes com seus nomes fictícios à descrição da formação acadêmica (quadro 2).

Quadro 2 - Formação Inicial dos Participantes da ACIEPE

\begin{tabular}{|l|l|}
\hline \multicolumn{1}{|c|}{ Nome } & \multicolumn{1}{c|}{ Formação } \\
\hline Carla & Cursando licenciatura em Ciências Biológicas - UFSCar \\
\hline Pedro & Cursando licenciatura em Ciências Biológicas - UFSCar \\
\hline Josias & Cursando licenciatura em Ciências Biológicas - UFSCar \\
\hline Fábio & Cursando licenciatura em Física - UFSCar \\
\hline Anne & Cursando licenciatura em Física - UFSCar \\
\hline Maria & Cursando licenciatura em Química - UFSCar \\
\hline Marla & Cursando licenciatura em Química - UFSCar \\
\hline Beatriz & $\begin{array}{l}\text { Licenciada em Ciências Biológicas; } \\
\text { Cursando mestrado em Educação em Ciências e Matemática - UFSCar }\end{array}$ \\
\hline Juliana & $\begin{array}{l}\text { Licenciada em Ciências Biológicas; } \\
\text { Cursando mestrado em Educação em Ciências e Matemática - UFSCar }\end{array}$ \\
\hline Gizele & $\begin{array}{l}\text { Licenciada em Pedagogia; } \\
\text { Professora aposentada da Rede de Ensino de Araras (formação inicial em Pedagogia) }\end{array}$ \\
\hline $\begin{array}{l}\text { Professora e } \\
\text { Pesquisadora }\end{array}$ & $\begin{array}{l}\text { Licenciada em Ciências Biológicas; } \\
\text { Cursando mestrado em Educação em Ciências e Matemática - UFSCar }\end{array}$ \\
\hline
\end{tabular}

Fonte: elaborado pelas autoras.

\section{Compreensões sobre aspectos científicos, tecnológicos e sociais relacionados à temática 'Raças Humanas'}

Desde o primeiro encontro, a partir das experiências e reflexões compartilhadas, diversas questões surgiram sobre a temática racial que nos permitiram problematizála e relacioná-la com o ensino de ciências. Uma representação de parte desse processo de compreensão e busca por relações pode ser visto nos tópicos que seguem.

\section{a. Aspectos estéticos}

A partir de um exemplo mencionado por Marla de seu cotidiano familiar, foram discutidas as pressões relacionadas aos padrões de beleza que estão presentes no cotidiano escolar desde os anos iniciais. Nesse momento, a discussão se baseou principalmente no caráter tipo de cabelo. O favorecimento social do fenótipo cabelo liso levou a diversas pressões quanto à adequação a esse padrão. A posição de Marla é de que não se deve alisar cabelos de crianças, mas sim ensiná-las a valorizar as suas próprias características. Outros participantes acrescentaram complexidade à questão ao considerarem a posição do (a) responsável pela criança (no caso, a mãe) e também as situações vividas pela própria criança vítima de preconceito.

As participantes Marla e Juliana parecem concordar com a valorização dos caracteres naturais da criança e com a não submissão a procedimentos estéticos de alisamento. Entretanto, Marla se mostrou mais firme em seu posicionamento, enquanto Juliana, mais flexível ao considerar a dificuldade envolvida na decisão de alisar ou não o cabelo. 


\begin{abstract}
Marla: Eu tenho uma priminha, ela tem 4 anos, e ela começou a ir na escolinha, e chegou em casa falando pra mãe: 'mãe, eu quero alisar meu cabelo e quero meu cabelo loiro'.

Juliana: Não é só entre os alunos que pode acontecer o preconceito. É também não ter a referência na historinha de criança, o que vai perpetuar esse erro, e também a postura das professoras. É aquele cabelo que a professora nunca coloca a mão [...].

Marla: A criança nem pede, a mãe já vai lá e alisa, porque a mãe já está com o cabelo liso e pintado de loiro. Entendeu? Pra mim aquilo lá é muito humilhante, porque é uma criança. Qual o problema de ela ter o cabelo cacheado? Tem que ensinar sua filha a gostar do cabelo dela! Mas a própria mãe vai lá e alisa o cabelo dela, que não é uma vergonha.

Juliana: É complicado, mas eu entendo o papel da mãe. Eu acho que está defendendo a filha, para ela não sofrer o que ela sofreu. [...] Quando a gente é criança, a gente está formando grupos e facilmente você é excluído de um grupo. Então... quando é criança, tem que ouvir um pouco, pensar. Vale a pena alisar ou deixar o cabelo enrolado? Vamos testando, mas eu acho assim... que a mãe tem que mostrar que é lindo o cabelo dela, mas é complicado.
\end{abstract}

Em sua fala, Carla contribui ainda mais para evidenciar o caráter controverso da questão. Enquanto mulher negra, conta fatos de sua experiência pessoal. Ela destaca que tais discussões são recentes e precisam avançar muito ainda, motivo pelo qual, pequenos avanços são comemorados como grandes acontecimentos, como é o caso do filme Pantera Negra, um filme de um super-herói negro que tem recebido grande destaque atualmente.

Carla: Essa questão estética, em relação à estética de negros e negras, ela está muito recente. Então, às vezes, essa mãe, dessa criança, nem ela se reconhece como bela... seu cabelo, a textura, a cor da pele. $O$ filme Pantera Negra, um elenco todo negro, e a representação... de um negro, que não é o negro que se representa até agora. Por que sempre tá tentando passar a perna em alguém, é um Negro totalmente desenvolvido, científico, e... Mano, é perfeito! [...] Eu tô feliz, porque eu nunca me vi desse jeito, sai chorando do filme. Hoje eu 'curto' meu cabelo, mas a minha mãe também, ela passava produto químico, nem sabia o que tinha dentro, quando eu era pequena. Sei lá, cinco anos de idade. É difícil mesmo, é um negócio que arde... fazia chapinha, queimava toda a testa, porque minha irmã que fazia. A gente chegava a colocar a cabeça na cama e passar o ferro. Ferro mesmo, de passar roupa. Não tinha chapinha. Colocava a toalha e passava o ferro. É uma coisa que ela mesmo não se reconhecia.

A partir das falas acima, podemos notar diversas questões que emergem do mundo da vida e que são expressas no cotidiano escolar. Carla utilizou exemplos da mídia e do seu próprio cotidiano familiar para argumentar, tal como Juliana, que a questão é mais complexa do que pode aparentar. Assim, não foi possível chegar a um consenso de uma normativa sobre a questão em discussão. É correto alisar o cabelo de uma criança? Embora nenhum participante tenha defendido que sim, nesse episódio ficou evidente a complexidade da questão e a imaturidade dessa discussão, que teve seu surgimento há pouco tempo. Ou seja, em questões como essa, os diversos fatores sociais envolvidos devem ser considerados. Ainda que essa decisão não diga respeito aos professores, discussões como essa podem contribuir para que os professores compreendam o cotidiano do aluno, assim como os dramas vividos por eles e possam desconstruir inclusive seus possíveis preconceitos.

Nessa discussão, foi identificada uma das componentes sociais que envolvem a questão racial, uma vez que negros lidam cotidianamente com a problemática relacionada aos padrões sociais de beleza. A componente social racial relacionada aos padrões de beleza, frequentemente se manifesta na escola. Os professores precisam 
estar preparados para reconhecer o preconceito em suas diferentes manifestações, superar seus próprios preconceitos e assumir uma postura antirracista.

Deste modo, consideramos que discussões como essa podem contribuir na formação de professores antirracistas. As discussões envolveram aspectos éticos e valorativos relacionados à temática racial. Segundo Zeidler et al. (2005), os professores devem estar preparados para enfrentar as situações éticas advindas das questões em discussão no contexto do ensino de ciências. Assim, compreendemos esse aspecto como uma contribuição à formação docente resultante da questão sociocientífica em discussão.

Para as ciências naturais, a diversidade biológica é de fundamental importância. A diversidade é valorizada e deve ser preservada. Isso porque além da necessidade de valorização da própria existência do que é singular, tal diversidade é crucial aos enfrentamentos que, enquanto espécie, somos submetidos. Ou seja, biologicamente, é melhor para o coletivo que sejamos diferentes. Assim, ao questionarmos os padrões estéticos de beleza atuais à luz dos conhecimentos científicos, podemos promover essa apreciação estética da natureza tal como ela é, sendo o ser humano, parte dessa natureza. As pressões do racismo estético, também se manifestam em produções científicas e tecnológicas, a exemplo da indústria dos químicos de alisamento. Por isso, a compreensão das relações CTS que envolvem essa questão sociocientífica são urgentes à educação.

\section{b. Compreensões sobre o racismo na produção científica e tecnológica}

Nos atos de fala que seguem foi possível observar a ação estratégica da professora pesquisadora, que objetivou estimular os participantes a pensarem em diferentes aspectos da temática racial. Juliana aceitou o convite à intersubjetividade e se inseriu novamente nesse processo formativo. Essa agente admitiu rapidamente reconhecer a relação da ciência com o "início do racismo" e revelou o seu desgosto em admiti-la.

Consideramos esse reconhecimento um primeiro passo para que possamos questionar a compreensão de ciência predominante nas universidades e no ensino de ciências. Ele representa uma brecha para a desconstrução dessa concepção. A fala da participante também expressa um resquício da concepção de ciência neutra e salvacionista, quando ao admitir a responsabilidade da ciência em relação à origem do racismo e reconhecê-la de outro modo expressou sua decepção.

Professora pesquisadora: Então... Por que a gente pensou na questão racial como uma questão sociocientífica? O que tem de científica essa questão? Vocês conseguem pensar em algo?

Juliana: O início do racismo é... científico, né, infelizmente. Odeio admitir isso.

Fábio: Eu estava pensando aqui agora. A tecnologia também não ajudou o racismo em si? Eu estava pensando aqui, em que sentido? Estou perguntando, porque eu não sei [trecho inaudível]. Eu não consigo ver, assim... Onde será que a tecnologia poderia entrar no racismo em si?

Juliana: Tem a questão da produção também. Quem produz? Porque tá lá? Tem aquele filme, Estrelas além do tempo, que vai retratar isso.

Anne: Eu não sei quanto aos negros, eu não sei muito dessa parte, mas às mulheres, tinha desde pesquisas mostrando o que o cérebro ser menor ou a cabeça ser menor. Significado? Vai ser mais burra ou não tão inteligente quanto os homens, por exemplo. Então era um jeito sim de diminuir as mulheres, tanto que várias pesquisas de mulheres, os homens ficaram encarregados, pegaram projetos, então eu não duvido 
nada que tenha isso com os negros, deve ter alguma coisa relacionada. Acho que não é só de agora, os estereótipos e tudo mais, acho que vem desde atrás.

Beatriz: Se você pensar, assim, acho... não a questão das pessoas negras, mas acho que as pessoas judias, no Holocausto, o tanto de pesquisas que foi desenvolvido naquela época. Tendo como base o quê? Estereótipo, religião, a descendência judia do fulano comparando com o branco alemão Ariano. Então, isso daí está desde muito tempo... Eu tinha dito... para justificar o racismo por trás da ciência. Ah, vamos fazer um experimento, vai que rola, vai que tem uma diferença. Então, você já está se justificando, e querendo ou não isso desenvolve tecnologia.

Nesse episódio foi possível observar a potencialidade do contexto comunicativo para a identificação de aspectos sociocientíficos da questão. Na fala de Fábio, podemos observar um processo inicial de percepção e comunicação sobre tais relações. Um professor que se proponha a abordar uma QSC com seus alunos pode ter maior ou menor aprofundamento nos diferentes aspectos que a envolvem. Nesse sentido, o contexto comunicativo pode contribuir para que diferentes agentes com diferentes olhares construam coletivamente conhecimentos sobre uma problemática comum. Assim, compreendemos que a fala de Fábio representa sua abertura ao processo formativo proposto ao engajar-se nesse exercício de compreensão, que ele mesmo admitiu ter sido desafiador em outros momentos de sua fala. Seus questionamentos iniciais revelam ainda uma insegurança sobre o conteúdo da fala, ao mesmo tempo que representam um convite ao engajamento dos demais participantes no processo formativo, que se é conduzido, principalmente, nas relações intersubjetivas que se estabelecem no grupo.

A partir dos questionamentos de Fábio, foi iniciado um processo reflexivo buscando entendimento sobre as relações do conceito de 'Raças Humanas', ciência e tecnologia. Isso ficou evidente nas falas que seguem, a começar pela fala da professora pesquisadora que buscou estabelecer tais relações, seguida pelo envolvimento das agentes Juliana, Anne e Beatriz. Assim, a abordagem comunicativa possibilitou o exercício coletivo de identificar e problematizar tais aspectos, o que como um exercício solitário poderia ser desanimador, mas em um contexto comunicativo possibilitou que buscassem o entendimento, por meio da intersubjetividade.

\footnotetext{
Ao falar de uma racionalidade intersubjetiva, Habermas abre caminho para que a educação escolar, enquanto tarefa típica da modernidade, incorpore a pluralidade das razões, sem cair no risco do relativismo, tampouco no risco de entender a razão apenas numa dimensão operativa. Se a racionalidade percorreu caminhos que a distorceram, a educação pode rearticular processos de aprendizagem de uma outra razão e preparar sujeitos com competência comunicativa. Isso significa reconhecer que não há previamente monopólios interpretativos e que a ação pedagógica passa a se orientar pela lógica do 'Verstehen'. (PRESTES, 1996, p. 71).
}

A teoria da Ação comunicativa pode contribuir tanto para o diagnóstico quanto para a resolução dos problemas sociais ao extrapolar os aspectos técnicos e instrumentais da racionalidade (HABERMAS, 2012a, 2012b). Assim, destacamos o contexto coletivo de reflexão e comunicação como uma potencialidade, pois uma das dificuldades dos professores ao trabalhar com QSC é identificar os aspectos controversos dessas questões, bem como os aspectos sociais que as envolvem, conforme relatado por Martínez Pérez e Carvalho (2012) e Duso (2015). 
As falas de Anne e de Beatriz inseriram na discussão questões éticas envolvendo a pesquisa com seres humanos. Essas falas representam a problematização das realizações científicas, apontando pesquisas que tiveram como bases ideológicas o machismo e a concepção de superioridade entre as raças.

Anne mencionou o seu conhecimento de casos de pesquisa que tinham por objetivo inferiorizar a mulher em relação ao homem. Pesquisas essas que tinham a pretensão de legitimar as relações de poder já existentes na sociedade. Partindo dessa problematização, discutimos que assim como ocorreram pesquisas científicas que expressaram uma superioridade entre gêneros, existiram pesquisas que se engajaram em legitimar uma superioridade entre raças. Anne indicou compreender o racismo como um processo que não se limita à atualidade, mas iniciado muito anteriormente. Nesse sentido, a fala de Beatriz acrescentou elementos à discussão ao mencionar o Holocausto e as diversas pesquisas da época, que tiveram bases ideológicas racistas.

As falas de Anne e Beatriz revelaram uma nova componente da problemática da questão. Até esse momento, as discussões raciais do grupo se limitavam ao racismo no que se relaciona à negritude. Nesse momento, na busca por compreender as diferentes componentes sociocientíficas da questão chegamos à discussão sobre o contexto do nazismo, sobretudo em relação ao sofrimento do povo judeu. Ao ampliar essa discussão, novos elementos passaram a ser considerados, tais como a produção científica e tecnológica que ocorreu em decorrência da subordinação de uma raça em relação à outra.

Nos trechos da fala de Beatriz "o tanto de pesquisas que foi desenvolvido naquela época [...] para justificar o racismo por trás da ciência", nos indica sua compreensão da natureza ideológica na produção científica no contexto nazista. Essa percepção é fundamental para o ensino de ciências tal como concebemos e para a formação de professores de ciências críticos.

Essas falas revelaram diversas possibilidades da temática racial para a formação de professores de ciências. Considerando que diversos cientistas contribuíram para a legitimação do ideal de superioridade entre raças, é possível discutir aspectos da natureza da ciência e também das questões éticas, morais e valorativas que envolvem o trabalho do cientista. Exemplos de acontecimentos como a escravidão no Brasil ou o holocausto na Alemanha, nos fornecem inúmeros elementos para essa discussão, tornando possível a construção de uma concepção menos ingênua da ciência a ser compreendida como um processo histórico.

\section{c. Discussões sobre os aspectos históricos do racismo no contexto brasileiro}

As falas a seguir iniciaram-se com a nossa tentativa de direcionar a discussão para o contexto brasileiro, ao inserir a questão da miscigenação. As participantes Juliana e Carla associam nossa problematização à ideia de embranquecimento da população brasileira.

Pesquisadora: Então, no Brasil é muito difícil, complicado, por uma questão que é justamente a miscigenação, uma forma de camuflar o racismo no Brasil. Mas afinal, quem é o negro no Brasil? É difícil, é difícil até mesmo se identificar.

Juliana: É a questão do branqueamento da população, que é uma das..., né? Nos Estados Unidos, uma gota sangue negro te torna negro, no Brasil uma gota de branco te torna branco. Então, você já quer 
se autodeclarar ... que você não é mais preto, você é moreno, você é pardo, isto é uma estratégia de branqueamento da sociedade brasileira. Tudo Branco hoje no Brasil, né? Deu super certo!

Carla: Nossa! Ótimo que seja miscigenado, filho de casal inter-racial, mas a gente tem que entender no começo era algo forçado, violento.

Juliana: Ejustificado, pela miscigenação.

Juliana destacou a miscigenação como um aspecto que diferencia o racismo brasileiro do estadunidense. A mesma discussão foi continuada por Fábio. Em sua fala, Fábio compartilhou experiências e observações sobre o intercâmbio que realizou recentemente nos Estados Unidos, por um ano.

Foi observado por Fábio a pouca representatividade negra na Universidade em que estudou durante o intercâmbio. Ainda que, segundo ele, os Angolanos com os quais estudou nesse período tivessem um ótimo desempenho acadêmico. A partir disso, Carla chamou a atenção para o fato de que as tecnologias africanas são pouco evidenciadas e os africanos subjugados a despeito de seus conhecimentos, muitas vezes avançados, assim como a comunicação em diferentes línguas, por exemplo. Assim, essa participante evidencia uma outra dimensão do racismo que se relaciona à ciência e à tecnologia, o racismo epistemológico.

Fábio: Mas é realmente diferente dos Estados Unidos, porque lá é muito forte essa questão.

Carla: Eu acho que cai também na parte do que a gente falou de Tecnologia, porque... o quanto do cultural que não é valorizado de tecnologias africanas. Tipo... tem coisa pra caramba que foi inventada na África e que a gente totalmente ignora e coisas mais [trecho inaudível] que seja que são: Nossa! As melhores coisas do mundo! Coisas foram inventadas na África, não é discutido, né?

Nas discussões de questões sociocientíficas, um aspecto fundamental a ser considerado é a discussão sobre a natureza da ciência. Nesse sentido, discussões sobre a história e filosofia da ciência devem ser incorporadas ao ensino. Diversos estudos têm apontado para a necessidade de se promover uma contextualização histórica da produção dos conhecimentos científicos ao ensinar ciências (CARNEIRO; GASTAL, 2005; MARTINS, 2007; MATTHEWS, 1994). As discussões sobre as políticas eugênicas da Alemanha nazista, sobre a política de embranquecimento da população brasileira e a realidade histórico-social dos Estados Unidos além de promover uma contextualização histórica, possibilitaram a análise crítica dos empreendimentos científicos.

No entanto, é válido ressaltar que a contextualização histórica do ensino de ciências conta com alguns cuidados, como evitar que a representação histórica dos conhecimentos científicos passe a ideia de linearidade, como um continuum e romper com a concepção de hierarquia e da maior complexidade da produção científica do presente em relação à do passado (BIZZO, 1992).

Contudo, a partir dos dados analisados, compreendemos que a discussão da QSC 'Raças Humanas' na perspectiva habermasiana contribuiu para a formação de professores de ciências de muitas maneiras. A contextualização histórica e social, o papel ativo do professor em sua formação, as discussões éticas e valorativas possibilitaram uma abordagem mais ampla do ensino de ciências e seus objetivos.

Por meio dos atos de fala, os agentes da pesquisa puderam exteriorizar suas preocupações e dar suas contribuições. Assim, as discussões foram enriquecidas e os resultados surpreendentes. Consideramos que esse processo tenha contribuído para o desenvolvimento docente. O modo como exteriorizam seus questionamentos 
e contribuições ao longo do desenvolvimento do curso, nos permite inferir que avançaram no que se refere à orientação racional de suas ações, no sentido da racionalidade instrumental à racionalidade comunicativa, ao pensar o ensino de ciências para além dos conteúdos curriculares abordados isoladamente, mas que envolva as suas inter-relações com questões sociais, tais como o racismo. Não queremos afirmar, com isso, que a partir de então outros modos de ações foram abandonados, predominando a ação comunicativa, mas que juntos, avançamos nesse sentido fortalecendo uma formação docente emancipatória.

\section{d. O racismo em piadas e brincadeiras}

A partir de diversos relatos expressos ao longo da ACIEPE, a preocupação com piadas e brincadeiras passou a ser cada vez mais evidente. As falas a seguir exemplificam momentos nos quais essa preocupação foi evidenciada.

\footnotetext{
Pedro: Eu estava pensando em casa sobre o que eu tinha no meu dia a dia. O que mais me incomodou, do que a gente discutiu aqui, foram as piadas que eu acabo escutando no dia a dia, com cunho relacionado à etnia. Para mim, já era uma coisa que me incomodava um pouco, eu sempre fui de me incomodar, mas depois que a gente teve a discussão aqui, que vocês trouxeram essas coisas como o exemplo do filme da Pantera Negra, das pessoas negras se sentirem mais aceitas com um filme de super-herói. Às vezes o racismo ele é sutil, né? Como nessas brincadeiras. A pessoa que faz uma piada, ela não sente, mas quem tá escutando, por mais que possa parecer uma brincadeira leve, entre aspas, né... acaba sendo aborrecido. Então, eu acho que isso deu para pensar bastante, no lado das brincadeiras... depois que a gente conversou.
}

Na fala "a pessoa que faz a piada, ela não sente, mas quem tá escutando, por mais que possa parecer uma brincadeira 'leve', entre aspas, né? Acaba sendo aborrecido", Pedro expressa sua percepção em relação à sutileza do racismo em nosso cotidiano. Sua fala destaca uma concepção muito comum no ideário racial do povo brasileiro que se traduz na leviandade com a qual consideramos as piadas racistas ou preconceituosas de modo geral. Grande parte das pessoas compreende esses fenômenos como algo inofensivo. Atualmente, o politicamente correto tem sido fortemente criticado e a espontaneidade valorizada, ainda que essa espontaneidade ofenda e agrida grupos minoritários.

Nas falas "o que mais me incomodou, do que a gente discutiu aqui..." e "então, eu acho que isso deu para pensar bastante, no lado das brincadeiras... depois que a gente conversou", Pedro fez referência à discussão do encontro anterior, o que nos indica que essas discussões foram importantes para a compreensão que estava exteriorizando naquele momento.

Os trechos "eu estava pensando em casa [...]" e "o que mais me incomodou [...]" nos indicam o envolvimento desse agente com o processo formativo, estendendo suas reflexões para além dos momentos dos encontros em sala. Também há indicativos de que esse agente buscasse ser compreendido pelo grupo no trecho "às vezes o racismo, ele é sutil, né? [...] por mais que possa parecer uma brincadeira leve, entre aspas, né... acaba sendo aborrecido". Compreendemos que nesse contexto, a utilização da expressão "né" ao final das afirmações reforçam a intenção de ser compreendido pelo grupo e de que a pretensão de validade levantada seja aceita por ele. 
Das falas desse agente, podemos identificar uma mudança em seu modo de compreender a temática, motivado pelo contexto comunicativo que participamos. Nos atos de fala seguintes, Pedro se utilizou de frases explicativas e exemplos pessoais para explicar seu ponto de vista. Ele usou exemplos pessoais e estabeleceu uma relação de analogia entre as brincadeiras sobre a situação vivenciada por ele (a depressão) e o racismo o que pode ser evidenciado no trecho "[...] porque é a mesma coisa, a pessoa negra não vai querer escutar uma piada de cunho racista". Esse agente também citou exemplos da mídia e levantou a pretensão de validade de "não fazer esse tipo de brincadeira". Tanto a professora pesquisadora quanto Beatriz complementam sua fala, seguindo a mesma linha de argumentação e aceitando a pretensão de validade proposta por ele.

Professora pesquisadora: 'Brincadeira' racial é tão naturalizada que a pessoa nem percebe quando faz uma brincadeira que isso atinge.

Beatriz: O problema é naturalizar isso, achar que pode levar adiante, que todo mundo pode falar que seu cabelo é ruim. Posso passar a mão no seu cabelo, sei lá. Isso é muito sério, invadir a privacidade da pessoa, o respeito, perde tudo né. É muito difícil!

Nos trechos de fala analisados, observamos que os participantes discutiram a problemática do racismo implícito em piadas e brincadeiras a partir das observações e reflexões pessoais do participante Pedro. A sensibilização do olhar para questões raciais permitiu a esse participante identificar questões antes não detectadas. Vemos em sua fala um processo de empatia quando se imagina como vítima do preconceito. Assim, as piadas antes consideradas inofensivas, parecem ganhar outro significado. Como em outro momento desse processo, esse participante traz suas inquietações para nossos momentos de formação coletiva. Esses dados representam, no contexto de nossa investigação, a possibilidade de que em grupo os professores analisem do ponto de vista ético e valorativo as situações com as quais possam vir a se deparar, tanto em sua vida pessoal quanto no cotidiano escolar.

\section{Conclusões}

Nesta investigação, nos propomos a analisar as implicações das discussões sobre 'Raças Humanas' e seus aspectos sociocientíficos na formação de professores de ciências. Nesse sentido, considerando que a QSC em discussão nos possibilitou realizar, junto aos professores, uma análise crítica de diversos aspectos do racismo no Brasil e suas relações com ciência e tecnologia. A discussão envolveu aspectos da história e natureza da ciência compreendendo suas dimensões éticas e valorativas. A partir dos dados analisados, foi possível observar a possibilidade de estabelecimento de relações intersubjetivas no contexto da formação de professores. Compreendemos a potencialidade dessas relações, pois ao contrastar diferentes percepções sobre uma patologia social, no caso, o racismo, os professores em formação puderam ampliar sua visão de mundo e construir novas compreensões diferentes das que seriam possíveis no âmbito da subjetividade e reflexão solitária.

Os dados constituídos nessa investigação indicaram a possibilidade de envolvermos os professores em formação na discussão de diversas questões que relacionam o racismo, ciência, sociedade e tecnologia. Foram evidenciadas questões suscitadas dessa discussão, tais como estética e padrões de beleza, a natureza 
ideológica da produção científica e tecnológica, a contextualização histórica sobre o racismo brasileiro, a invisibilidade da problemática, a sutileza com que pode se manifestar em piadas e brincadeiras.

Nesse sentido, os aspectos do racismo discutidos pelos docentes contribuíram para uma maior percepção das patologias sociais aumentando assim as possibilidades de intervenção no sentido de minimizar seus efeitos e contribuir para seu combate. Entretanto, ao mesmo tempo em que em nossa pesquisa os espaços comunicativos se mostraram potenciais para minimizar os efeitos do isolamento profissional e para o combate ao racismo mediante a formação crítica, ética e valorativa dos docentes, consideramos a dificuldade de estabelecimento de tais espaços frente à sobrecarga de trabalho docente e à falta de tempo para encontros frequentes de formação. Nesse sentido, consideramos ainda a existência de muitas barreiras a serem superadas na formação de professores, sobretudo aquelas relacionadas à luta pela profissionalização docente.

A perspectiva participante e comunicativa favoreceu o estabelecimento de um espaço democrático. Essa perspectiva esteve alinhada às ideias habermasianas, ao possibilitar uma busca por entendimento a partir das discussões intersubjetivas da QSC 'Raças Humanas'. O envolvimento dos participantes da pesquisa na investigação também representou um aspecto formativo, por favorecer o envolvimento intelectual dos docentes e a colaboração mútua. Nesse sentido, consideramos que foi possível a construção coletiva de uma nova visão sobre a QSC objeto de nossa discussão. Por fim, consideramos que a discussão sobre a temática racial e seus aspectos sociocientíficos representa uma grande contribuição para a formação docente, ao nos permitir, em uma perspectiva habermasiana, (re) pensar tal formação, tendo em vista aspectos éticos e valorativos que nos permitam promover a democracia e a justiça social. Entretanto, compreendemos que ainda há muito a se avançar na área de pesquisa do ensino de ciências a esse respeito. Nesse sentido, enxergamos na perspectiva comunicativa possibilidades promissoras para que os diferentes agentes educacionais possam se unir para uma efetiva transformação social no que se refere ao racismo.

\section{Agradecimentos}

Agradecemos à Coordenação de Aperfeiçoamento de Pessoal de Nível Superior (CAPES), Código de Financiamento 001, pela subvenção desta pesquisa.

\section{Referências}

BAROLLI, E.; VILLANI, A. A formação de professores de ciências no Brasil como campo de disputas. Revista Exitus, Santarém, PA, v. 5, n. 1, p. 72-90, 2015. Disponível em: https://cutt.ly/BnKO7sB.

Acesso em: 26 jun. 2020.

BIZZO, N. Eugenia: quando a biologia faz falta ao cidadão. Cadernos de Pesquisa, São Paulo, n. 92, p. 38-52, 1995. Disponível em: https://cutt.ly/rnKPs1Z. Acesso em: 26 jun. 2020.

BIZZO, N. História da ciência e ensino: onde terminam os paralelos possíveis? Em Aberto, Brasília, v. 11, n. 55, p. 29-35, 1992. Disponível em: https://cutt.ly/QnLDXFE. Acesso em: 26 jun. 2020. 
BRASIL. Lei no 1390, de 3 de julho de 1951. Inclui entre as contravenções penais a prática de atos resultantes de preconceitos de raça ou de cor. Disponível em: http://www.planalto.gov.br/ ccivil_03/LEIS/L1390.htm. Acesso em: 08 dez. 2019.

BRASIL. Lei $n^{\circ} 7716$, de 05 de janeiro de 1989. Define os crimes resultantes de preconceito de raça ou de cor. Disponível em: http://www.planalto.gov.br/ccivil_03/leis/l7716.htm. Acesso em: 26 jun. 2020.

CARNEIRO, M. H. D. S.; GASTAL, M. L. História e filosofia das ciências no ensino de biologia. Ciência \& Educação, Bauru, v. 11, n. 1, p. 33-39, 2005. DOI: https://doi.org/10.1590/1516731320190030012.

CERQUEIRA, D.; LIMA, R. S.; BUENO, S.; VALENCIA, L. I.; HANASHIRO, O.; MACHADO, P. H. G.; LIMA, A. S. Atlas da violência 2017. Rio de Janeiro: IPEA, 2017. Disponível em: https://cutt.ly/MnLFxez. Acesso em: 26 jun. 2020.

CERQUEIRA, D. et al. Atlas da violência 2018. Rio de Janeiro: IPEA, 2018. Disponível em: https:// cutt.ly/jnLFQZJ. Acesso em: 26 jun. 2020.

CONTRERAS, J. A autonomia de professores. São Paulo: Cortez, 2002.

DIAS, T. L. S.; FERNANDES, K. M.; ARTEAGA, J. S.; SEPÚLVEDA, C. Genética, raça e políticas de ações afirmativas a partir de questões sociocientíficas. In: VI SIMPÓSIO NACIONAL DE CIÊNCIA, TECNOLOGIA E SOCIEDADE, 6., 2015, Rio de Janeiro. Anais [...]. Rio de Janeiro: UFRJ, 2015. Disponível em: https://cutt.ly/vnLGvaW. Acesso em: 26 jun. 2020.

DUSO, L. A discussão de controvérsias sociocientíficas: uma perspectiva integradora no ensino de ciências. 2015. 245 f. Tese (Doutorado em Educação Científica e Tecnológica) - Universidade Federal de Santa Catarina, Florianópolis, 2015. Disponível em: https://repositorio.ufsc.br/xmlui/ handle/123456789/160651. Acesso em: 26 jun. 2020.

GAJARDO, M. Pesquisa participante: propostas e projetos. In: BRANDÃO, C. R. (org.). Pesquisa participante. São Paulo: Brasiliense, 1987. p. 15-50.

GOMES, L. R. Educação e comunicação em Habermas: o entendimento como mecanismo de coordenação da ação pedagógica. Cadernos de Educação, Pelotas, n. 33, p. 231-250, maio 2009. Disponível em: https://cutt.ly/RnLHyLx. Acesso em: 26 jun. 2020.

HABERMAS, J. Teoria do agir comunicativo: racionalidade da ação e racionalização social. São Paulo: WMF Martins Fontes, 2012a.

HABERMAS, J. Teoria do agir comunicativo: sobre a crítica da razão funcionalista. São Paulo: WMF Martins Fontes, 2012b.

LONGAREZI, A. M.; SILVA, J. L. Pesquisa-formação: um olhar para sua constituição conceitual e política. Revista Contrapontos, Itajaí, v. 13, n. 3, p. 214-225, 2013. DOI: https://doi.org/10.14210/ contrapontos.v13n3.p214-225.

LOPES, N. C. Aspectos formativos da experiência com questões sociocientíficas no ensino de ciências sob uma perspectiva crítica. 2010. 230 f. Dissertação (Mestrado em Educação para a Ciência) Faculdade de Ciências, Universidade Estadual Paulista, Bauru, 2010. Disponível em: http://hdl. handle.net/11449/90954. Acesso em: 3 mar. 2019.

MACIEL, M. E. S. A eugenia no Brasil. Anos 90, Porto Alegre, n. 11, p. 121-143, jul. 1999. Disponível em: https://cutt.ly/cnLJ1uZ. Acesso em: 22 abr. 2019.

MARTINS, A. F. P. História e filosofia da ciência no ensino: há muitas pedras nesse caminho. Caderno Brasileiro de Ensino de Física, Florianópolis, v. 24, n. 1, p. 112-131, 2007. Disponível em: https://cutt.ly/rnLKqCM. Acesso em: 10 jun. 2019. 
MARTÍNEZ PÉREZ, L. F.; CARVALHO, W. L. P. Contribuições e dificuldades da abordagem de questões sociocientíficas na prática de professores de ciências. Educação e Pesquisa, São Paulo, v. 38, n. 3, p. 727-741, 2012. DOI: https://doi.org/10.1590/S1517-97022012005000014.

MATTHEWS, M. R. Historia, filosofía y enseñanza de las ciencias: la aproximación actual. Enseñanza de las Ciencias, Barcelona, v. 12, n. 2, p. 255-277, 1994. Disponível em: https://cutt.ly/ anLKX8G. Acesso em: 8 ago. 2018.

MÜHL, E. H. Habermas e a educação: racionalidade comunicativa, diagnóstico crítico e emancipação. Educação \& Sociedade, Campinas, v. 32, n. 117, p. 1035-1050, 2011. DOI: https://doi. org/10.1590/S0101-73302011000400008.

MUNANGA, K. Nosso racismo é um crime perfeito: entrevista a Camila Souza e Glauco Faria. Revista Fórum, Brasil, v. 77, 9 fev. 2012. Disponível em: https://cutt.ly/VnLCrTQ. Acesso em: 2 de set. 2018.

PENA, S. D. J.; SILVA, D. R. C.; SILVA, J.; PRADO, V.; SANTOS, F. R. O retrato molecular do Brasil. Ciência Hoje, Rio de Janeiro, v. 27, n. 159, p. 16-25, 2000.

PENA, S. D. J. Razões para banir o conceito de raça da medicina brasileira. História, Ciências, Saúde-Manguinhos, Rio de Janeiro, v. 12, n. 2, p. 321-346, 2005. DOI: https://doi.org/10.1590/ S0104-59702005000200006.

PRESTES, N. H. Educação e racionalidade: conexões e possibilidades de uma razão comunicativa na escola. Porto Alegre: Edipucrs, 1996.

RATCLIFFE, M.; GRACE, M. Science education for citizenship: teaching socio-scientific issues. Philadelphia: Open University Press, 2003.

SANTOS, R. V.; MAIO, M. C. Qual "retrato do Brasil"?: raça, biologia, identidades e política na era da genômica. Mana, Rio de Janeiro, v. 10, n. 1, p. 61-95, 2004. DOl: https://doi.org/10.1590/S010493132004000100003.

SCHMIDT, M. L. S. Pesquisa participante: alteridade e comunidades interpretativas. Psicologia USP, São Paulo, v. 17, n. 2, p. 11-41, 2006. DOI: https://doi.org/10.1590/S0103-65642006000200002.

SOMEKH, B.; LEWIN, C. Teoria e métodos de pesquisa social. Petrópolis: Vozes, 2015.

UNIVERSIDADE FEDERAL DE SÃO CARLOS. Pró-Reitoria de Extensão. Edital para realização de atividades curriculares de integração ensino, pesquisa e extensão a serem realizadas no primeiro semestre de 2018. São Carlos: UFSCar, 2018. Disponível em: https://cutt.ly/YnL4onT. Acesso em: 13 jul. 2018.

ZEIDLER, D. L.; SADLER, T. D.; SIMMONS, M. L.; HOWES, E. V. Beyond STS: a research-based framework for socioscientific issues education. Science Education, Salem, v. 89, n. 3, p. 357-377, 2005. DOI: https://doi.org/10.1002/sce.20048. 